\title{
Hemispheric asymmetries of affective processing as determined by the Minnesota Multiphasic Personality Inventory
}

\author{
W I L L I A G . G A S P R R I N I, P A U L S A T Z, \\ KENNETH M. HEILMAN, A N F FEDERICK L. COOLIDGE \\ From the Department of Clinical Psychology, College of Health Related Professions, \\ the Department of Neurology, College of Medicine, University of Florida, \\ and the Veterans Administration Hospital, Gainesville, Florida, USA
}

SUMMARY Patients with left hemisphere disease have been noted to be depressed while those with right hemisphere disease appear indifferent. While patients with left hemisphere disease frequently have a greater cognitive deficit, patients with right hemisphere disease have difficulty in expressing affectively intoned speech. The Minnesota Multiphasic Personality Inventory (MMPI) can demonstrate underlying affective experience and is not dependent on affectively intoned speech. The purpose of this study was to determine whether a difference in affective moods, as assessed by the MMPI, was related to laterality of lesion in patients matched for severity of cognitive and motor dysfunction. Seven of the 16 subjects with left hemisphere dysfunction and none of the eight subjects with right hemisphere dysfunction showed an elevation on the depression scale. This observation not only confirms previous clinical observations but also demonstrates that these asymmetries cannot be ascribed completely to hemisphererelated differences in cognitive deficits or expressive abilities.

Goldstein (1948) noted that patients with left hemisphere brain damage often have increased emotional behaviour, and appear anxious and depressed. Hécaen et al. (1951) and Denny-Brown and associates (1952) observed that patients with right hemisphere lesions appear to be inappropriately indifferent. Gainotti (1972) studied the emotional reactions of 160 patients with lateralised brain damage, and his findings supported earlier observations that patients with left hemisphere damage suffer a depressive catastrophic reaction while those with right hemisphere damage show emotional indifference.

This study was presented in part at the International Neuropsychological Society Meeting in Santa Fe, New Mexico, February 1976.

The work was supported in part by US Public Health Service, National Institutes of Health, Grant NS 12218-01AZ.

Address for reprint requests: Dr Heilman, Department of Neurology, Box J-236, Medical Science Building, University of Florida, Gainesville, Florida, 32610, USA.

Accepted 27 December 1977
Heilman and associates (1975) found that right hemisphere-damaged patients with the indifference reaction were unable to recognise affectively intoned sentences-that is, not what is said, but how it is said. Tucker et al. (1976) demonstrated that right hemisphere-impaired patients had an inability to disdriminate between identical and different affective intonations and to produce affectively toned speech. Comprehension and expression of affect in spoken statements require discrimination of pitch, tempo, inflection, and stress (Paul, 1909). Blumstein and Cooper (1974) have documented a right hemisphere advantage for processing intonation contours, and Carmon and Nachson (1973), using a dichotic listening technique in normal subjects, found that emotional tones were processed better when given to the left ear than to the right. Unlike right hemisphereimpaired patients who cannot express emotional tones, aphasics who have impaired propositional speech may be more dependent on emotional 
intonations for expression (Hughlings Jackson, 1879). Since there are evocative asymmetries between right and left hemisphere-impaired patients, it is possible that the emotional asymmetries previously described (Goldstein, 1948; Hécaen et al., 1951; Denny-Brown et al., 1952; Gainotti, 1972) are not related to differences of affect but rather to the evocative strategies imposed by defects of intonational (right hemisphere-impaired) or propositional (left hemisphere) speech.

The Minnesota Multiphasic Personality Inventory (MMPI) is a structured questionnaire consisting of 566 statements which an individual endorses as true or false about himself (Hathaway and McKinley, 1951). Empirically derived from both patient and normal subjects, it purports to measure the presence of a variety of psychopathological problems. Ten clinical scales and three validity scales are scored. The 10 clinical scales represent clusters of items which, if endorsed, are related to the presence of complaints seen in the following psychiatric disorders: hypochondrias, depression, hysteria, sociopathy, gender role identification, paranoia, psychasthenia, schizophrenia, hypomania, and social introversion/extroversion. The MMPI can demonstrate the underlying affective experience of a patient and is not dependent on reception or cvocation of auditory intonation contours.

Early studies on emotional changes after brain damage compared patients with frontal lobe damage and patients with parietal lobe damage (Anderson and Hanvik, 1950). When comparing the profiles of these groups of patients, there were no significant differences. Vogel (1962) tested the effects of a number of variables on degree of psychopathological changes (measured by the MMPI) after brain damage. With 37 braindamaged subjects, he found no relationship in the MMPI between degree of pathological findings and laterality or locus of lesion. Unfortunately, Vogel compared his left versus right braindamaged groups with a chi-squared test on the basis of what proportion of the subjects in each of the two groups had more than three clinical MMPI scales elevated above a $T$ score of 70 . This method of statistical analysis does not get at the crucial difference in elevation on scale 2 (depression) with sufficient power to determine whether or not it actually occurred in Vogel's sample. Meier and French (1965) studied 20 patients with either right or left temporal lobe EEG abnormalities. Although no differences in $\mathrm{T}$ scores were observed between the groups, the nonsignificant trend on the depression scale (2) was in the direction of greater depression with left hemisphere damage.
Dikmen and Reitan (1974) also failed to find a relationship between lesion localisation and MMPI profile in their 59 subjects with localised cerebral lesions. Reitan (1976) concludes that, despite the frequency with which clinicians and researchers have postulated that the right hemisphere is the "emotional hemisphere" of the brain, there is no evidence from any of the studies based on MMPI results that any such differentiation is valid.

Recently, Black (1975) compared the MMPI profiles of 15 subjects with right hemisphere disease with 20 subjects with left hemisphere disease. Although patients with left hemisphere disease showed more depression, they also had a greater cognitive defect which may have induced the depression.

The purpose of this study was to determine whether a difference in affective moods, assessed by the MMPI, was related to laterality of lesion in patients equated for severity of cognitive dysfunction.

\section{Subjects and method}

The subjects in this study were 24 consecutive brain-damaged patients with lateralised lesions who completed the MMPI as part of a battery of tests used in the Neuropsychology Laboratory at the University of Florida Medical Center. Based on neurological examination, electroencephalography, and neuroradiological procedures, 16 patients were classified as having left hemisphere dysfunction, and eight as having right hemisphere dysfunction. The aetiological basis of hemisphere dysfunction in the right hemisphere-impaired patients was: post-traumatic (two), vascular (one), tumour (one), focal idiopathic seizures (four). The aetiological basis of the left hemisphere dysfunction was: post-traumatic (four), vascular (four), tumour (two), focal idiopathic seizures (six). In the left hemisphere-impaired group, 12 patients had their dysfunction in the temporal lobe, one in the frontal lobe, one in the parietal region, and in two patients the intrahemispheric location of the lesion could not be determined. In the right hemisphere group, five patients had temporal lobe dysfunction, one parieto-occipital dysfunction, and in two the localisation could not be determined. To ensure that any emotional differences between groups were not due to differences in severity of neuropsychological or motor deficits, we excluded aphasics (except for two subjects with mild word-finding difficulty), and we compared the two groups on several variables from the neuropsychological test battery. The results are presented in Table 1. 
Table 1 Age and education of subjects and results of neuropsychological tests

\begin{tabular}{|c|c|c|c|c|}
\hline & \multicolumn{2}{|c|}{$\begin{array}{l}\text { Side of brain } \\
\text { damage }\end{array}$} & \multirow[b]{2}{*}{$\boldsymbol{F}$} & \multirow[b]{2}{*}{$P$ valu } \\
\hline & $\begin{array}{l}\text { Left } \\
(n=16)\end{array}$ & $\begin{array}{l}\text { Right } \\
(n=8)\end{array}$ & & \\
\hline Age (yr) & 36.5 & 41.4 & 1.95 & 0.18 \\
\hline Education & 13.4 & 14.6 & 0.18 & 0.68 \\
\hline Verbal IQ & 105.1 & 106.0 & 0.10 & 0.76 \\
\hline Performance IQ & 100.9 & 101.2 & 0.21 & 0.65 \\
\hline Full Score IQ & 103.5 & 104.1 & 0.17 & 0.68 \\
\hline Finger tapping, right hand & 42.3 & 42.9 & 0.22 & 0.64 \\
\hline Finger tapping, left hand & 39.5 & 38.0 & 0.15 & 0.70 \\
\hline Form Board, correct-right & 8.2 & 8.3 & 0.07 & 0.79 \\
\hline Form Board, correct-left & 8.6 & 8.6 & 0.32 & 0.58 \\
\hline
\end{tabular}

A multivariate analysis of variance on these control variables revealed no significant difference between the two groups $(F=0.89, P<0.58)$. Individual analyses of variance similarly revealed no significant differences between the groups in age, education, Wechsler Adult Intelligence Scale IQ, speed of finger tapping, or performance on a form board test. Although there was a nonsignificant trend towards the right hemisphere group being older, the correlation between age and the depression scale (2) was not significant $(r=0.04)$.

\section{Results}

A multivariate analysis of variance was used to compare the profiles of the two groups on the 10 clinical scales of the MMPI. A significant difference between the profiles $(F=2.76, P<0.05)$ was observed, and this permitted individual analyses of variance, comparing the two groups on each of the 10 scales. Of the 10 clinical MMPI scales, only scale 2 (depression) revealed a significant difference between left and right hemisphere braininjured groups $(\mathrm{F}=7.02, \mathrm{P}<0.02)$. Interestingly, seven of 16 subjects with left hemisphere brain damage $(43.75 \%)$ scored in the abnormal range on scale 2 ( $\mathrm{T}$ score $>70$ ), whereas not one of the eight subjects with right hemisphere brain damage scored above 70 on that scale.

Table 2 shows the mean scores on each of the clinical MMPI scales for the two groups and the percentage of patients in each group with abnormal elevations on each scale. The mean MMPI profile of the 16 subjects with left hemisphere brain damage revealed a 2-8-7 configural pattern. This is compatible with a major affective disorder. Patients who obtain profiles similar to the mean profile of the left hemisphere brain-damaged group often show withdrawal, unrealistic feelings of anxiety, agitation, rumination, and suicidal preoccupation.
Table 2 Mean MMPI scale scores and percentage of patients in pathological range

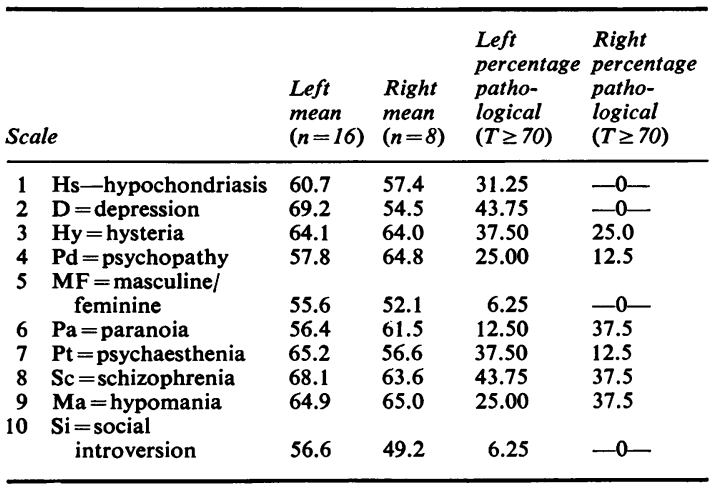

\section{Discussion}

We are not certain why our results are different from those of Rietan (1976), but our data lend credence to the hypothesis that left hemisphere lesions are associated with more depression than right hemisphere lesions.

Goldstein (1948) suggested that the depressive catastrophic reaction of left hemisphere aphasic patients might be related to feelings of helplessness and inability to perform certain basic kinds of tasks. Gainotti (1972) made similar observations. Since neuropsychological testing of all patients in both groups revealed that there was no incidence of detectable aphasia in the left hemisphere-damaged group, and that the two groups did not differ significantly in manual dexterity, logical memory, verbal IQ, performance IQ, or any other neuropsychological variable measured (Table 1), the difference in depressive affect between the two groups cannot be explained as a function of differential motor or cognitive impairment.

Since the MMPI does not require the comprehension or expression of emotional tones-that is, how it is said-the previously noted asymmetries of emotional response cannot be completely ascribed to an evocative-expressive disorder. Although the present study revealed differences in emotional behaviour after hemispheric dysfunction and showed that these hemispheric differences are not produced by differences in cognitive, motor, or intonational processing, it has not elucidated the nature of the emotional asymmetries. We hope that future studies would provide additional information on the nature of these hemispheric differences. 


\section{References}

Anderson, A. L., and Hanvik, L. J. (1950). The psychometric localisation of brain lesions. The differential effect of frontal and parietal lesions on MMPI profile. Journal of Clinical Psychology, 6, 177-180.

Black, F. W. (1975). Unilateral brain lesions and MMPI performance: a preliminary study. Perceptual Motor Skill, 40, 87-93.

Blumstein, S., and Cooper, W. E. (1974). Hemispheric processing of intonation contours. Cortex, 10, 146158.

Carmon, A., and Nachson, I. (1973). Ear asymmetry in perception of emotional non-verbal stimuli. Acta Psychologica (Amsterdam), 37, 351-357.

Denny-Brown, D., Meyer, J. S., and Horenstein, S. (1952). The significance of perceptual rivalry resulting from parietal lesion. Brain, 75, 433-471.

Dikmen, S., and Reitan, R. M. (1974). MMPI correlates of localised cerebral lesions. Perceptual Motor Skills, 39, 831-840.

Gainotti, G. (1972). Emotional behaviour and hemispheric side of lesion. Cortex, 8, 41-55.

Goldstein, K. (1948). Language and Language Disturbances. Grune and Stratton: New York.

Hathaway, S. R., and McKinley, J. C. (1951). The
Minnesota Multiphasic Personality Inventory Manual. Psychological Corporation: New York.

Hécaen, H., de Ajuriaguerra, J., and Massonet, J. (1951). Les troubles visuo-constructif par lésion parieto-occipitale droite. Encephale, 40, 122-179.

Heilman, K. M., Scholes, R., and Watson, R. (1975). Auditory affective agnosia. Journal of Neurology, Neurosurgery, and Psychiatry, 38, 69-72.

Hughlings Jackson, J. (1879). On affection of speech from disease of the brain. Brain, 2, 203-222.

Meier, M. J., and French, L. A. (1965). Some personality correlates of unilateral and bilateral EEG abnormalities in psychomotor epileptics. Journal of Clinical Psychology, 31, 3-9.

Paul, H. (1909). Principien der Sprachgeschichte. Fourth edition. Halle AS: Niemeyer.

Reitan, R. M. (1976). Neurological and physiological bases of psychopathology. Annual Review of Psychology, 27, 189-216.

Tucker, D. M., Watson, R. T., and Heilman, K. M. (1976). Affective discrimination and evocation in patients with right parietal disease. Neurology (Minneapolis), 27, 947-950.

Vogel, W. (1962). Some effects of brain lesions on MMPI profiles. Journal of Consultative Clinical Psychology, 26, 412-415. 